\title{
PERANCANGAN APLIKASI PENYEDIA JASA KHUSUS RENTAL MOBIL BERBASIS ANDROID
}

\author{
Ahmad Fauzi ${ }^{1}$, Dewi Leyla Rahmah ${ }^{2}$, Aulia Ar Rakhman Awaludin ${ }^{3}$ \\ Program Studi Teknik Informatika, Fakultas Teknik dan Ilmu Komputer, \\ Universitas Indraprasta PGRI \\ Jalan Raya Tengah No 80, Kelurahan Gedong, Pasar Rebo, Jakarta Timur \\ fauzi6409@gmail.com ${ }^{1}$,dewileyla.dl@gmail.com² ${ }^{2}$ aulia_awaludin@yahoo.co.id ${ }^{3}$
}

\begin{abstract}
Abstrak
Perkembangan ilmu pengetahuan dan teknologi saat ini berkembang sangat pesat. Kemajuan akan ilmu pengetahuan dan teknologi telah berperan penting di dalam masyarakat. Setiap waktu, setiap hari dan setiap detik selalu muncul teknologi baru. Tujuan penelitian adalah untuk membuat sebuah aplikasi yang efektif bagi CV. Obet Cipta Usaha dalam penyewaan mobilnya. Aplikasi membantu perusahaan dalam mengelola data-data karyawan, supir, mobil dan transaksi dengan mudah sehingga proses penyewaan mobil lebih cepat dan efisien. Sehingga laporan data di atas dapat langsung di lihat pada aplikasi. Aplikasi ini juga membantu pelanggan untuk melakukan penyewaan mobil dan mengetahui informasi tentang ketersediaan mobil yang akan di sewa tanpa harus datang ke tempat. Penelitian ini menggunakan metode kualitatif, yaitu suatu penelitian kontekstual yang menjadikan manusia sebagai instrumen, dan disesuaikan dengan situasi yang wajar dalam kaitannya dengan pengumpulan data yang pada umumnya bersifat kualitatif. Hasil penelitian ini berupa aplikasi yang digunakan dalam penyewaan mobil. Jadi peneliti ini telah berhasil membuat aplikasi penyedia jasa khusus rental mobil berbasis android yang bertujuan untuk membantu pengguna memudahkan dalam melakukan penyewaan mobil tanpa harus datang ke tempat.
\end{abstract}

Kata Kunci: Perancangan, Android, Rental Mobil, Penyedia Jasa, Aplikasi

\begin{abstract}
The development of science and technology today is growing very rapidly. Advances in science and technology have played an important role in society. Every time, every day and every second new technology comes up. The purpose of research is to create an effective application for the CV. Obet Cipta Usaha in his car rental. The app helps companies manage the data of employees, drivers, cars and transactions easily so that the car rental process is faster and more efficient. So that the data report above can be directly seen in the application. The app also helps customers to do car rental and know information about the availability of the car to be rented without having to come to the place. This research uses qualitative methods, which are contextual studies that make humans as instruments, and adapted to reasonable situations in relation to data collection that is generally qualitative. The results of this study are in the form of applications used in car rentals. So, this researcher has succeeded in creating an android-based car rental service provider application that aims to help users facilitate in doing car rental without having to come to the place.
\end{abstract}

Keywords: Design, Android, Car Rental, Service Provider, Application

\section{PENDAHULUAN}

Perkembangan ilmu pengetahuan dan teknologi saat ini berkembang sangat pesat. Kemajuan akan ilmu pengetahuan dan teknologi telah berperan penting di dalam masyarakat. Setiap waktu, setiap hari dan setiap detik selalu muncul teknologi baru. Salah satunya adalah teknologi mobile yang terkenal di masyarakat, telah banyak mempengaruhi kehidupan. Peran teknologi juga dirasakan banyak perusahaan, seperti contohnya pada CV.Obet Cipta Usaha. CV. Obet Cipta Usaha adalah usaha yang bergerak di bidang jasa, yang menawarkan rental mobil murah dengan pelayanan yang mewah. Dengan banyaknya perusahaan penyewaan mobil yang menawarkan rental mobil murah membuat setiap perusahaan bersaing untuk mendapatkan konsumen. Manusia tidak lepas dari transportasi untuk melakukan kehidupan sehari-hari. Tidak semua perusahaan rental mobil mempunyai kantor yang strategis untuk memasarkan dan mendapatkan konsumen. Diharapkan dengan adanya aplikasi ini bisa menjembatani antara konsumen dengan perusahaan agar mudah di akses di manapun dan kapanpun secara langsung. Maka dari itu diperlukan sistem yang baik untuk pemesanan mobil tersebut yang akan memberikan kemudahan, ketepatan dan kecepatan di dalam memberikan informasi kepada pelanggan dan semua pihak yang membutuhkan. Berdasarkan hasil tinjauan objek penelitian, diperlukan suatu sistem informasi yang mampu mendukung dan dapat 
mempermudah dalam menyajikan informasi dan pemesanan mobil yang dapat langsung diakses melalui perangkat mobile berbasis Android oleh para pelanggan. Berdasarkan hal tersebut, maka peneliti mengambil judul "Perancangan Aplikasi Penyedia Jasa Khusus Rental Mobil Berbasis Android". perancangan adalah sebuah proses untuk mendefinisikan sesuatu yang akan melibatkan deskripsi mengenai arsitektur serta detail komponen dikerjakan dengan menggunakan teknik yang bervariasi serta didalamnnya dan juga keterbatasan yang akan dialami dalam proses pengerjaannya (Soetam Rizky, 2011). Aplikasi adalah satu unit perangkat lunak yang dibuat untuk melayani kebutuhan akan beberapa aktivitas seperti sistem perniagaan, game, pelayanan masyarakat, periklanan, atau semua proses yang hampir dilakukan oleh manusia (Pramana, 2012) Sistem informasi terdiri dari komponen- komponen yang disebut dengan istilah blok bangunan, yang terdiri dari blok masukan, blok model, blok keluaran, blok teknologi, blok basis data, dan blok kendali, sebagai suatu sistem. Keenam blok tersebut saling berinteraksi satu dengan yang lain membentuk satu kesatuan untuk mencapai sasaran (Sutabri, 2012). Android merupakan sistem operasi untuk perangkat telepon selular berbasis Linux. Android menyediakan platform terbuka bagi para pengembang untuk menciptakan aplikasi mereka sendiri untuk digunakan oleh bermacam piranti bergerak. Android umum digunakan di smartphone dan juga tablet PC. Fungsi Android sama seperti sistem operasi Symbian di Nokia, IOS di Apple dan Blackberry OS (Harahap, 2012). Android umum digunakan di smartphone dan juga tablet PC. Fungsi Android sama seperti sistem operasi Symbian di Nokia, IOS di Apple dan Blackberry OS (Safaat, 2011).

\section{PENELITIAN RELEVAN}

Penelitian yang menjadi dasar pengembangan aplikasi pengenalan budaya Indramayu adalah hasil dari pemikiran peneliti itu sendiri dengan beberapa sumber penelitian sebelumnya yang pernah dilakukan oleh Eka Siti Nurjanah, (2018) dalam penelitian ini berisi tentang pemesanan online cuci kendaraan pada Steam CBA Eka Jaya berbasis Android sebagai media pendidikan karakter bagi mahasiswa karena kearifan lokal mempunyai arti sangat penting bagi anak didik kita. Nilai-nilai kerja keras, pantang mundur, dan tidak kenal menyerah perlu diajarkan pada generasi penerus kita (Nurjanah, 2018).

Penelitian yang dilakukan Adam Saputra (2014) media pembelajaran dipandang sebagai salah satu aspek yang memiliki peranan pokok dalam pembentukan generasi di masa mendatang. Untuk membuat media pembelajaran yang menarik dengan merancang sebuah aplikasi android dan metode yang digunakan dalam perancangan aplikasi ini adalah waterfall. Dimana model ini telah terorganisasi secara teratur sehingga resiko akan terjadinya pengulangan proses langkah kerja akan terhindar sebab dilakukan secara berurutan (Saputra et al, 2014). Penelitian oleh Kusniyati dan Pangondian Sitanggang (2016) dengan judul Aplikasi edukasi Budaya Toba Samosir Berbasis Android. Hasil dari penelitian tersebut adalah aplikasi untuk mempermudah penggunanya mengakses bebagai informasi kebudayaan Toba Samosir melalui aplikasi edukasi budaya Toba Samosir berbasis Android ini. Banyak dari lapisan masyarakat sekarang ini telah menggunakan teknologi informasi dan komunikasi sebagai salah satu sektor kompetitif yang bisa menambah nilai dari proses bisnis yang dijalankan ( Kusniyati \& Pangondian Sitanggang, 2016).

\section{METODE PENELITIAN}

Penelitian ini menggunakan metode kualitatif, metode penelitian pada dasarnya merupakan cara ilmiah untuk mendapatkan data tujuan Dan kegunaan tertentu. Baik berupa data primer maupun data sekunder yang dapat digunakan untuk menyusun karya ilmiah dan kemudian menganalisis faktor-faktor yang berhubungan dengan pokok-pokok permasalahan sehingga akan didapat suatu kebenaran atas data yang diperoleh (Sugiyono 2008). Metode pengembangan sistem menggunakan Waterfall, merupakan metode pengembangan perangkat lunak yang selalu diperkenalkan kepada mahasiswa jurusan ilmu komputer/teknik informatika melalui suatu matakuliah. Hal ini mengakibatkan metode Waterfall hampir selalu digunakan sebagai metode untuk pengembangan perangkat lunak (Binato, 2014).

Penelitian ini menggunakan metode kualitatif, yaitu suatu penelitian kontekstual yang menjadikan manusia sebagai instrumen, dan disesuaikan dengan situasi yang wajar dalam kaitannya dengan pengumpulan data yang pada umumnya bersifat kualitatif. Penelitian kualitatif adalah penelitian berdasarkan mutu atau kualitas dari tujuan sebuah penelitian itu. Penelitian kualitatif adalah 
penelitian yang di desain secara umum yaitu penelitian yang dilakukan untuk objek kajian yang tidak terbatas dan tidak menggunakan metode ilmiah menjadi patokan (Sukardi, 2013). Teknik pengumpulan data yang digunakan oleh peneliti dalam melakukan pengumpulan data:

1. Observasi dan Penelitian Lapangan

Metode ini dilakukan dengan cara pengamatan langsung di Obet Rent Car dalam memperoleh data-data secara langsung pada objek yang diperlukan.

2. Wawancara

Metode ini dilakukan melalui tatap muka langsung dan tanya jawab dengan pihak terkait yang berhubungan dengan penelitian atau sumber data. Serta mengajukan pertanyaan-pertanyaan kepada Bapak Syamsudin (Obet) selaku pemilik Obet Rent Car. Dengan metode ini data dapat diperoleh secara langsung oleh narasumber.

3. Kearsipan

Metode pengumpulan data ini dilakukan dengan mempelajari arsip dan dokumen-dokumen yang telah ada. Arsip dan dokumen yang diperoleh kemudian dianalisa apakah bisa dijadikan sumber basis data atau tidak.

4. Metode Kepustakaan

Metode pengumpulan data ini dilakukan dengan membaca referensi, literature dan catatan penting lainnya sesuai permasalahan yang dihadapi peneliti. Dari bahan-bahan tersebut diambil teori-teori yang dapat dijadikan landasan untuk menganalisa masalah yang ditemukan dalam penelitian.

\section{HASIL DAN PEMBAHASAN}

Flowchart atau diagram alir adalah sebuah jenis diagram yang mewakili algoritma, alir kerja atau proses yang menampilkan langkah-langkah dalam bentuk simbol-simbol grafis dan urutannya dihubungkan dengan panah. Diagram ini mewakili ilustrasi atau penggambaran penyelesaian masalah. Diagram alir digunakan untuk menganalisis, mendesain, mendokumentasi, dan memanajemen sebuah proses atau program di belakang bidang. Flowchart pada aplikasi pengenalan budaya Indramayu sebagai berikut:

\section{Flowchart Splash Screen}

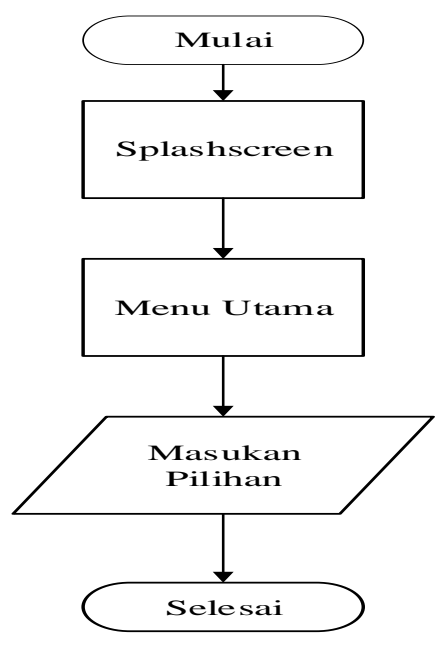

Gambar 1. Flowchart Splash Screen 


\section{Flowchart Menu Utama}

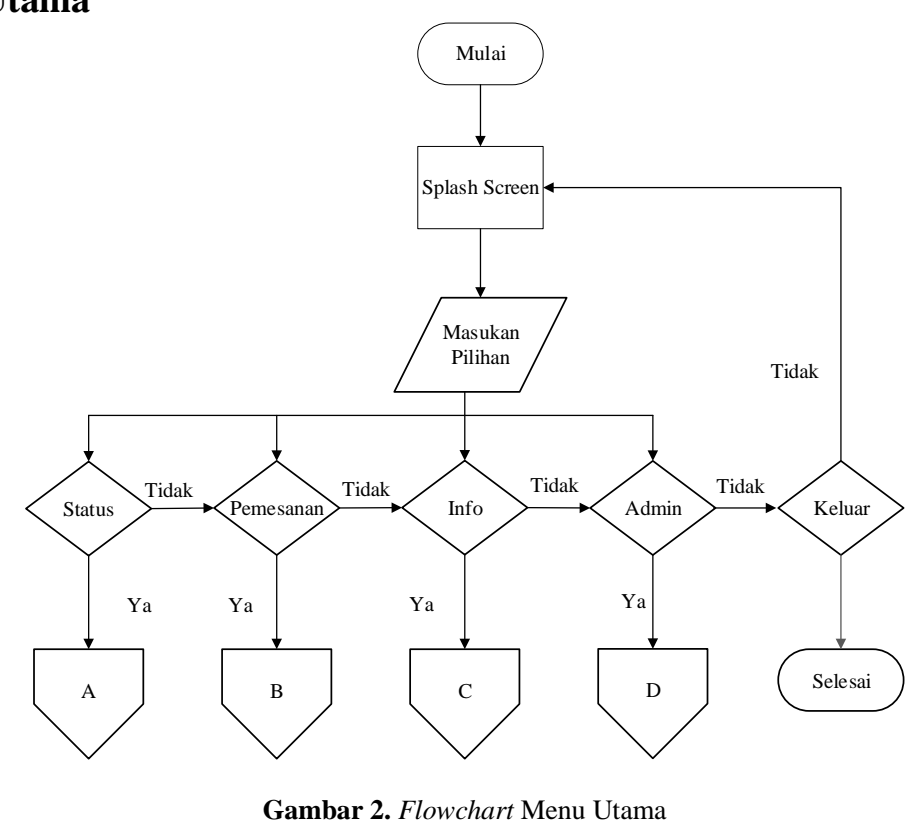

\section{Flowchart Pemesanan}

\section{Flowchart Mobil}

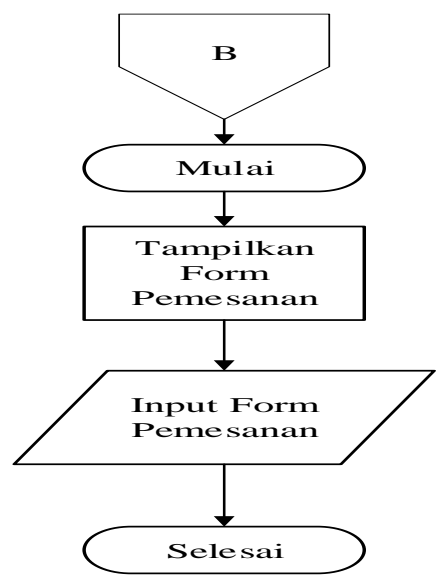

Gambar 3. Flowchart Pemesanan

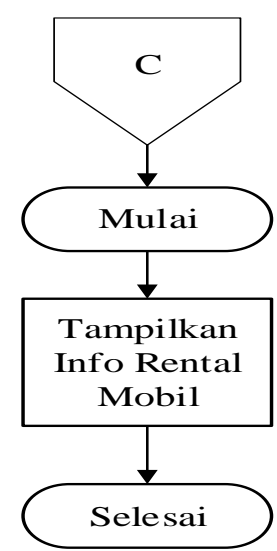

Gambar 4. Flowchart Mobil 


\section{Flowchart Status}

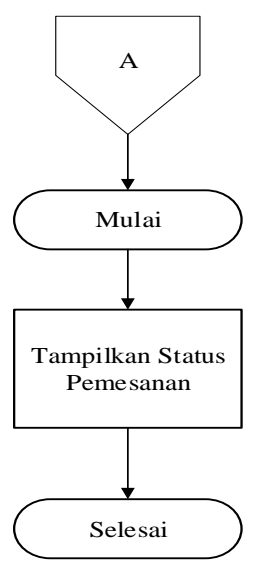

Gambar 5. Flowchart Status

\section{Flowchart Menu Admin}

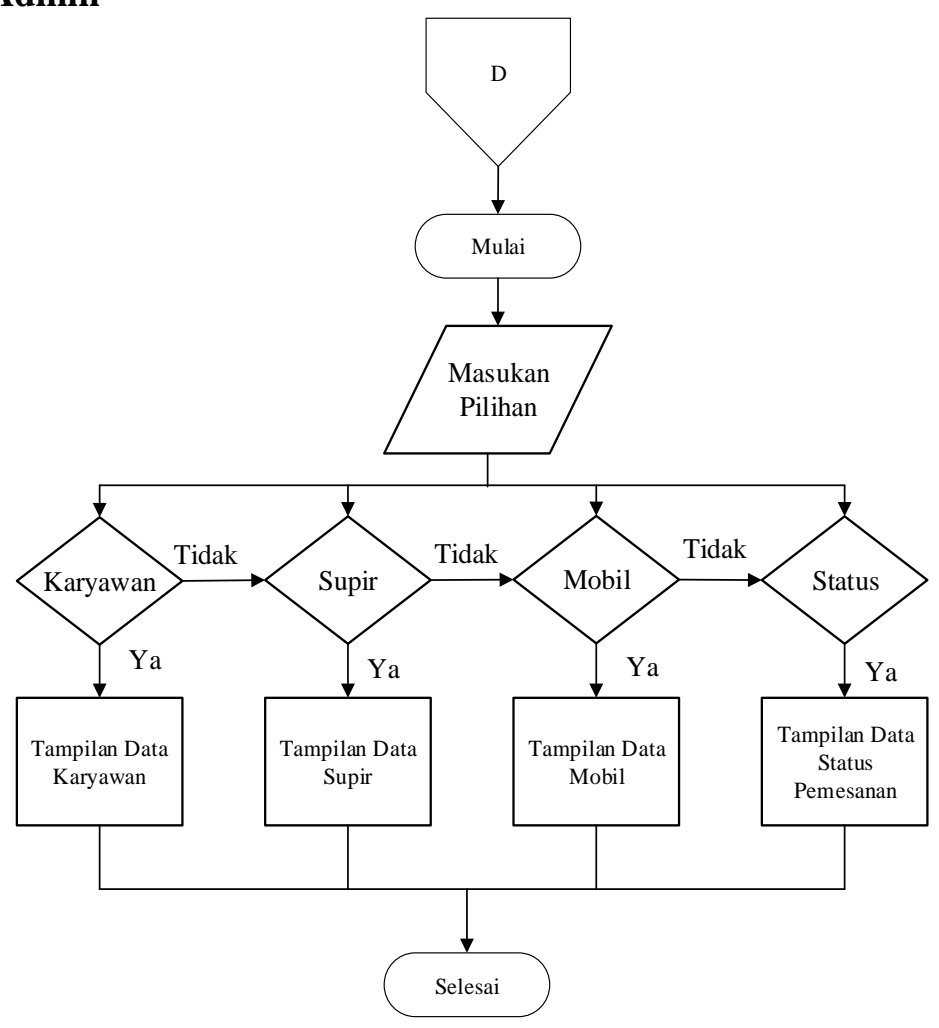

Gambar 6. Flowchart Menu Admin 


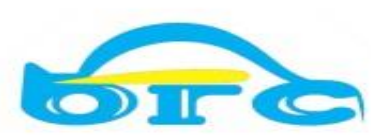

Gambar 7. Tampilan Layar Splash Screen

Merupakan tampilan awal yang pertama kali muncul saat membuka aplikasi sebelum ke menu utama. Setelah menunggu beberapa detik kemudian akan langsung dialihkan menuju menu utama.

\section{Tampilan Menu Utama}
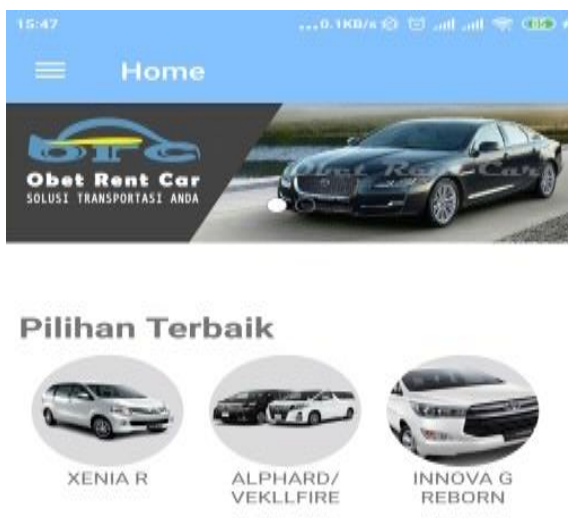

Gambar 8. Tampilan Layar Menu Utama

Merupakan menu yang muncul setelah splash screen, Pada tampilan menu utama, terdapat penampilan mobil-mobil yang akan disewakan Di menu utama juga terdapat menu drawer yang menampilan menu-menu yang ada pada aplikasi ini, berikut ini adalah gambar tampilan menu drawer ketika klik icon hamburger diatas: 


\section{Tampilan Mobil}

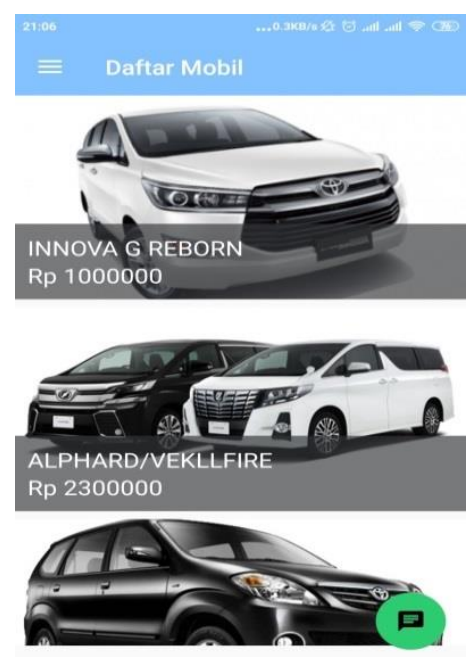

Gambar 9. Tampilan Layar Mobil

Pada tampilan menu daftar mobil ketika mengklik menu daftar mobil di menu drawer terdapat daftar mobil yang akan disewakan.

\section{Tampilan Pemesanan}
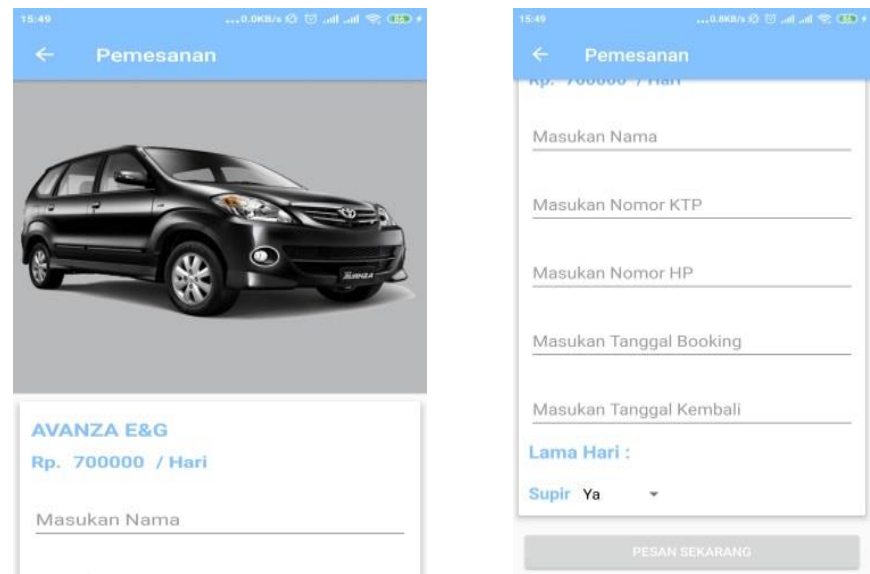

Gambar 10. Tampilan Layar Pemesanan

Pada tampilan pemesanan ini terdapat form yang harus di lengkapi oleh pengguna. Ketika sudah terisi semua, user bisa menekan tombol submit untuk memesan.

\section{Tampilan Status}

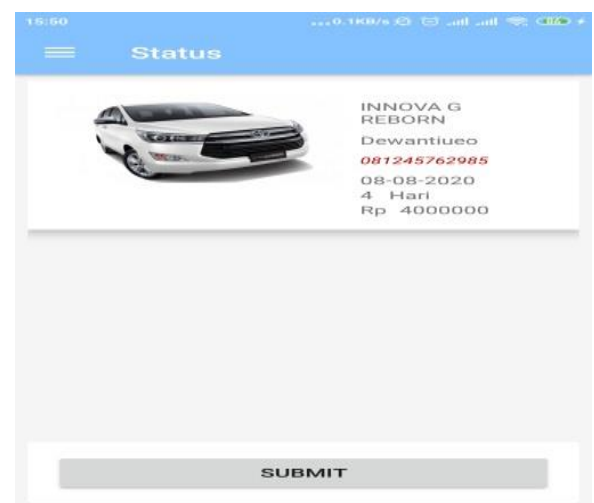

Gambar 11. Tampilan Status 
Pada tampilan status ini terdapat tampilan mobil yang akan disewakan dan total harga yang harus dibayar. tombol button untuk menyelesaikan langkah terakhir pemesanan.ketika pemesanan selesai, kemudian aplikasi akan otomatis membuat struk pemesanan yang berbentuk pdf untuk diberikan kepada admin nantinya.

\section{SIMPULAN}

Simpulan dari penelitian yang berjudul Perancangan Aplikasi Penyedia Jasa Khusus Rental Mobil Berbasis Android adalah sebagai berikut Aplikasi mobile rental mobil ini membantu pelanggan di ObetRentCar untuk melakukan penyewaan mobil dan mengetahui informasi tentang ketersediaan mobil yang akan disewa tanpa harus datang ke rental mobil kembali. Dengan mobile aplikasi ini pengelola dapat mengelola data mobil, pelanggan, dan supir dan pemesanan dengan mudah sehingga proses penyewaan mobil lebih cepat dan efisien. Aplikasi ini dapat berjalan dengan baik dan menghasilkan output sesuai dengan yang diharapkan. Sehingga secara fungsional dari sistem yang telah diimplementasikan dapat menghasilkan informasi data kendaraan dan jasa yang tersedia.

\section{DAFTAR PUSTAKA}

Binanto, I. (2014). Analisa Metode Classic Life Cycle ( Waterfall ) Untuk Pengembangan Perangkat Lunak Multimedia. Jurnal Universitas Sanata Dharma Yogyakarta. https://doi.org/10.13140/2.1.1586.4968

P Harahap, N. S. (2012). Pemrograman Aplikasi Mobile Smartphone dan Tablet PC Berbasis Android. Bandung: Informatika

Kusniyati, H., \& Pangondian Sitanggang, N. S. (2016). Aplikasi Edukasi Budaya Toba Samosir Berbasis Android. Jurnal Teknik Informatika. https://doi.org/10.15408/jti.v9i1.5573

Nurjanah, E.S. 2018. Perancangan Aplikasi Cuci Kendaraan Dan Pemesanan Online Pada Steam CBA Eka Jaya Berbasis Android. Jakarta: Universitas Indraprasta PGRI.

Pramana, H. W. (2012). Aplikasi Inventory Berbasis Access 2003. Jakarta: PT. Elex Media Komputindo.

Rizky, Soetam. 2011. Konsep Dasar Rekayasa Perangkat Lunak. Jakarta: Prestasi Pustaka.

Saputra, A., Beny, \& Nugroho, A. (2014). Perancangan Edukasi Pengenalan Nama Hewan Dalam Bahasa Inggris (Studi Kasus : Sdn.58/Vii Teluk Rendah Sarolangun). Jurnal Ilmiah Media Processor, 9(1), 54-66.

Safaat, N. (2011). Pemrograman Aplikasi Mobile Smartphone dan Tablet PC Berbasis Android. Bandung : Informatika Bandung. In Android.

Sugiyono. (2010). Metode Penelitian Bisnis. Pendekatan Kuantitatif, kualitatif dan R \& D. Bandung: Alfabeta.

Sutabri, T. (2012). Konsep Sistem Informasi. In Jurnal Administrasi Pendidikan UPI. 